Final version published in the Journal of System Assurance Engineering and Management (ISSN 0975-6809), volume 7, issue 1, pages 99-113.

DOI: $\underline{10.1007 / s 13198-015-0380-4}$ 


\section{International Journal of Systems Assurance Engineering and Management An expert-based approach to production performance analysis of oil and gas facilities considering time-independent Arctic operating conditions \\ --Manuscript Draft--}

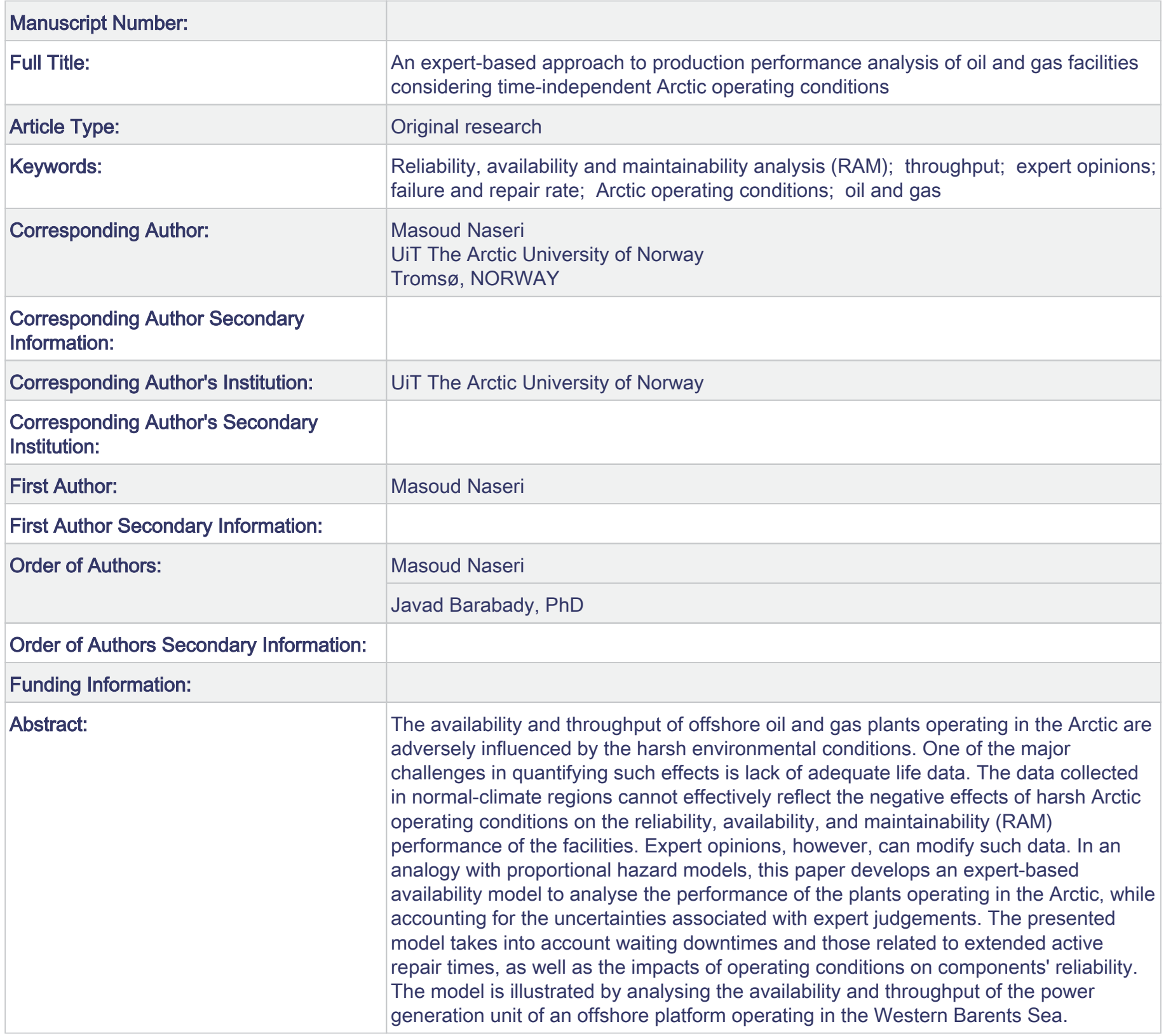




\title{
An expert-based approach to production performance analysis of oil and gas facilities considering time-independent Arctic operating conditions
}

\author{
Masoud Naseri*1, Javad Barabady ${ }^{1}$ \\ ${ }^{1}$ Department of Engineering and Safety, UiT - The Arctic University of Norway, PO box 6050, Lagnes, 9037 \\ Tromsø, Norway \\ * Corresponding author: email: masoud.naseri@uit.no; Tel: (47)77660327; Address: Department of Engineering \\ and Safety, UiT - The Arctic University of Norway, PO box 6050, Lagnes, 9037 Tromsø, Norway
}

\section{Acknowledgement}

The authors would like to thank the anonymous experts for their participation in this study.

\begin{abstract}
The availability and throughput of offshore oil and gas plants operating in the Arctic are adversely influenced by the harsh environmental conditions. One of the major challenges in quantifying such effects is lack of adequate life data. The data collected in normal-climate regions cannot effectively reflect the negative effects of harsh Arctic operating conditions on the reliability, availability, and maintainability (RAM) performance of the facilities. Expert opinions, however, can modify such data. In an analogy with proportional hazard models, this paper develops an expert-based availability model to analyse the performance of the plants operating in the Arctic, while accounting for the uncertainties associated with expert judgements. The presented model takes into account waiting downtimes and those related to extended active repair times, as well as the impacts of operating conditions on components' reliability. The model is illustrated by analysing the availability and throughput of the power generation unit of an offshore platform operating in the Western Barents Sea.
\end{abstract}

Key words: Reliability, availability and maintainability analysis (RAM); throughput; expert opinions; failure and repair rate; Arctic operating conditions; oil and gas.

$\begin{array}{ll}\begin{array}{l}\text { Acronyms } \\ \text { CDF }\end{array} & \text { Cumulative distribution function } \\ \text { DM } & \text { Decision maker } \\ \text { FTTF } & \text { First time to failure } \\ \text { GEN } & \text { Generator } \\ \text { GT } & \text { Gas turbine } \\ \text { MC } & \text { Monte Carlo } \\ \text { MTTF } & \text { Mean time to failure } \\ \text { MTTR } & \text { Mean time to repair } \\ \text { O\&G } & \text { Oil and gas } \\ \text { ORDA } & \text { Offshore reliability data }\end{array}$


PDF

PHM

RAM

TR

TTF

TTR

\section{Notation}

E

$E^{\prime}$

$F_{i, E}^{D M}(\varepsilon)$

$F_{i, \Delta}^{D M}(\delta)$

$F_{T D T}^{(A)}(t)$

$F_{T T F}^{(B)}(t)$

$F_{\text {TTR }}^{(A)}(t)$

$F_{W D T}(t)$

$F_{\Phi}^{D M}(\psi)$

$F_{\Phi}^{j}(\psi)$

$m$

m

$m^{\prime}$

$m_{j}$

$m^{D M}$

$\operatorname{MTTF}_{B}$

$\operatorname{MTTR}_{B}$

$N_{C}$

$N_{e}$

$N_{S}^{1}$

$N_{S}^{2}$
Probability density function

Proportional hazard model

Reliability, availability, and maintainability

Train

Time to failure

Time to repair

Degree of increase in MTTR of a component operating in an Arctic location. In other words, component MTTR increases by a factor of $(1+E)$. In $E_{i}$, subscript $i$ refers to component $i$.

Time-independent factor by which component active repair rate is decreased due to the effects of Arctic operating conditions on maintenance crew performance.

Decision maker's CDFs of random variables $E$ (i.e., the degree of increase in a component's MTTR) corresponding to component $i$. Decision maker's CDF of random variable $\Delta$ (i.e., the degree of reduction in a component's MTTF) corresponding to component $i$.

The CDF of total downtimes, including active repair times and waiting downtimes, corresponding to a component, whose repair is performed under Arctic operating environment.

Failure probability function of a component operating in the base area. In $F_{T T F}^{(A)}(t)$, superscript $A$ refers to the Arctic.

CDF of active TTRs of a component in the Arctic offshore

CDF of waiting downtimes

Decision maker's CDF of unknown random variable $\Phi$

Expert $j$ 's CDF of unknown random variable $\Phi$

Mean of the natural logarithm of WDTs

Vector of the means of normal distributions fitted to experts' data Mean of the lognormal distribution of WDTs, $F_{W D T}(t)$

Mean of the normal distribution fitted to the data given by expert $j$

Mean of DM's distribution obtained by Bayesian aggregation of experts' distributions

Mean time to failure of a component operating in the base area. In $M T T F_{A}$, subscript $A$ refers to the Arctic.

MTTR of a component operating in the base area. In $M T T R_{A}$, subscript $A$ refers to the Arctic.

Total number of system components

Total number of experts

Number of required samples drawn from DM's CDFs $F_{i, \Delta}^{D M}(\delta)$ and $F_{i, E}^{D M}(\varepsilon)$ to effectively represent uncertainties in system availability and throughput results

Number of required samples from waiting downtime and active repair distributions to form the distribution of total downtime 


\begin{tabular}{|c|c|}
\hline$P G S_{S}$ & Power generation scenario s \\
\hline$T D T$ & $\begin{array}{l}\text { Total downtime corresponding to each corrective maintenance } \\
\text { task, which includes both waiting downtime and active repair time }\end{array}$ \\
\hline TTR & Active time to repair \\
\hline$w_{j}$ & Expert $j$ 's weighting factor \\
\hline$W D T$ & $\begin{array}{l}\text { Waiting downtime corresponding to each corrective maintenance } \\
\text { task }\end{array}$ \\
\hline$y_{j}$ & Experience of expert $j$ in years \\
\hline$\beta_{B}$ & $\begin{array}{l}\text { Shape parameter of a Weibull failure probability function of a } \\
\text { component operating in the base area. In } \beta_{A} \text {, subscript } A \text { refers to } \\
\text { the Arctic. }\end{array}$ \\
\hline$\Delta$ & $\begin{array}{l}\text { Degree of reduction in MTTF of a component in an Arctic } \\
\text { location. In other words, component MTTF reduces by a factor of } \\
(1-\Delta) \text {. In } \Delta_{i} \text {, subscript } i \text { refers to component } i \text {. }\end{array}$ \\
\hline$\Delta^{\prime}$ & $\begin{array}{l}\text { Time-independent factor by which component failure rate } \\
\text { increases due to the effects of operating environment }\end{array}$ \\
\hline$\zeta_{1}$ & A random number drawn from uniform distribution over $(0,1)$ \\
\hline$\zeta_{2}$ & A random number drawn from uniform distribution over $(0,1)$ \\
\hline$\eta_{B}$ & $\begin{array}{l}\text { Scale parameter of a Weibull failure probability function of a } \\
\text { component operating in the base area. In } \eta_{A} \text {, subscript } A \text { refers to } \\
\text { the Arctic. }\end{array}$ \\
\hline$\lambda_{B}(t)$ & $\begin{array}{l}\text { Weibull failure rate of a component operating in the base area. In } \\
\lambda_{A}(t) \text {, subscript } A \text { refers to the Arctic. }\end{array}$ \\
\hline$\mu_{B}$ & $\begin{array}{l}\text { Active repair rate of a component operating in the base area. } \mu_{B} \\
\text { refers to the active TTRs and excludes other waiting downtimes. } \\
\text { In } \mu_{A} \text {, subscript } A \text { refers to the Arctic. }\end{array}$ \\
\hline$\rho_{j k}$ & Correlation coefficient of the data given by experts $j$ and $k$ \\
\hline$\sigma$ & Standard deviation of the natural logarithm of WDTs \\
\hline$\sigma^{\prime}$ & $\begin{array}{l}\text { Standard deviation of the lognormal distribution of WDT s, } \\
F_{W D T}(t)\end{array}$ \\
\hline$\sigma_{j}$ & $\begin{array}{l}\text { Standard deviation of the normal distribution fitted to the data } \\
\text { given by expert } j\end{array}$ \\
\hline$\sigma^{D M}$ & $\begin{array}{l}\text { Standard deviation of DM's distribution obtained by Bayesian } \\
\text { aggregation of experts' distributions }\end{array}$ \\
\hline$\Sigma$ & Covariance matrix representing the correlation among experts \\
\hline$\left\{\Delta_{j i, 5 \%}, \Delta_{j i, 50 \%}, \Delta_{j i, 95 \%}\right\}$ & $\begin{array}{l}\text { The } 5^{\text {th }}, 50^{\text {th }} \text {, and } 95^{\text {th }} \text { quantiles of the degree of reduction in } \\
\text { MTTF of component } i \text {, given by expert } j\end{array}$ \\
\hline$\left\{E_{j i, 5 \%}, E_{j i, 50 \%}, E_{j i, 95 \%}\right\}$ & $\begin{array}{l}\text { The } 5^{\text {th }}, 50^{\text {th }} \text {, and } 95^{\text {th }} \text { quantiles of the degree of increase in MTTR } \\
\text { of component } i \text {, given by expert } j\end{array}$ \\
\hline
\end{tabular}

\section{Introduction}

Analysing the reliability, availability, and maintainability (RAM) of offshore oil and gas (O\&G) facilities operating in the Arctic is of crucial importance in order to provide sufficient information for decision makers (DMs) with respect to provision of risk-reducing measures, cost-benefit assessments, plant modifications, and implementing winterisation procedures. Historical data on the failure and repair of system components form the cornerstone of such assessments. However, while offshore O\&G industry expands their activities in the Arctic, 
providing adequate life data for RAM assessment of facilities is a major challenge (Barabadi et al. 2015). That is mainly because $O \& G$ industry has less experience in Arctic locations compared to normal-climate regions. Large variations in the operating conditions of different Arctic offshore areas (ISO 2010; Naseri and Barabady 2013) pose even greater challenges to developing a unique solution for system analysis purposes.

The Arctic offshore is associated with particular operating conditions such as long winter seasons, low temperature, the presence of sea ice and icebergs, atmospheric and sea-spray icing events, snowdrifts, heavy fog, large year-round climate variations, and polar low pressures (Barabadi and Markeset 2011; Gudmestad and Karunakaran 2012; Løset et al. 1999; Naseri and Barabady 2013). Such conditions can negatively affect equipment RAM performance by increasing the failure rate of system components and extending repair times. In this regard, the use of the life data collected in normal-climate regions does not result in satisfactory RAM assessments for systems operating in Arctic regions as such data do not reflect the impact of Arctic operating conditions on system performance.

Several studies have modelled the impact of operating environment on equipment reliability (Ansell and Philipps 1997; Barabadi and Markeset 2011; Dale 1985; Jardine et al. 1987; Kumar and Klefsjö 1994) and maintainability (Artiba et al. 2005; Barabadi et al. 2011a; Barabadi and Markeset 2011; Gao et al. 2010), using proportional hazard models (PHMs). The lack of a model to predict system availability is a drawback in these studies. Barabadi et al. (2011b) use a stratification approach for throughput capacity, while PHM is employed to include the effects of the operating environment. The aforementioned studies, however, mainly rely on an extensive range of life data and their corresponding environment, which is rarely available for Arctic O\&G facilities. Moreover, performing reliability and accelerated life tests to quantify the impact of operating conditions may not be feasible due to cost considerations.

To cope with such an issue, Naseri and Barabady (2015) have used expert judgements to predict the reliability of offshore O\&G facilities operating in the Arctic. They use expert opinions to account for the effects of harsh operating conditions on the reliability of system components. The use of an expert judgement process instead of PHMs presents a number of advantages. Namely, experts can form their judgements based on implicit models that consider the various effects of operating conditions on different failure mechanisms and repair tasks. Besides, since such effects are usually complex, uncertain, and interrelated (e.g. low temperatures, humidity, and atmospheric icing are interrelated meteorological phenomena (ISO 2001)), modelling the correlations among explanatory variables (i.e., the elements of Arctic operation conditions) adds an extensive analysis burden and requires even more life data to produce statistically significant results. Experts, however, can reflect upon the worst- and bestcase scenarios or express their judgements in the form of a distribution to include the uncertainties associated with their judgements as well as the year-round variations in operating conditions (Naseri and Barabady 2015). However, the aforementioned study does not discuss 
the effects of operating conditions on components' repair rates and thus does not present a model for system availability assessment.

The aim of this study is to analyse the RAM and throughput performance of the systems operating under Arctic climatic conditions. For this purpose, the expert-based reliability model, developed by Naseri and Barabady (2015), is adapted as the basis of the system RAM and throughput model. Life data collected in normal-climate conditions (i.e., base area) are used to model base failure and repair rates. Expert judgements are further used to include the effects of Arctic operating conditions by modifying components' base rates. Such modified failure and repair rates are then used to analyse the system RAM and throughput by adapting a direct Monte Carlo (MC) simulation approach, through which the propagation of uncertainties associated with expert opinions is analysed.

This study discusses system downtimes in terms of active repair times and other waiting downtimes. Expert judgements are aggregated using a weighted arithmetic average with two different expert weighting schemes, as well as a Bayesian technique. The proposed model is illustrated by analysing the amount of electricity produced by the power generation unit of an offshore Arctic O\&G production facility. The originality of this study lies in the development of time-independent expert-based availability and throughput models for Arctic O\&G facilities, which are able to account for the impact of the operating environment, as well as investigating the influence of different experts' data aggregation techniques on plant production estimation.

The rest of this paper is organised as follows: Section 2 describes the adapted expert-based reliability model and develops the expert-based repair rate model by combining the distribution of waiting downtimes and expert-based distribution of active repair times. Section 3 develops a step-by-step approach to MC simulation of system reliability, availability and throughput that uses the expert-based failure and repair rates. Section 4 offers a discussion of the case study, in which a linear opinion pool and Bayesian paradigms are used to aggregate expert judgements. System performance is further analysed using obtained DM's distributions. Section 5 presents the concluding remarks.

\section{Expert-based failure and repair rates}

\subsection{Modelling expert-based failure rate}

A two-parameter Weibull distribution is used to develop the component failure rate as it is a versatile distribution and capable of modelling different failure patterns including increasing, decreasing, and constant failure rates (Murthy et al. 2004; Rausand and Høyland 2004; Stapelberg 2009). Let times to failure (TTFs) of a component operating under normal environmental conditions (i.e., operating conditions of the base area) be Weibull distributed with $\beta_{B}>0$ and $\eta_{B}>0$ being its shape and scale parameters, respectively, and index $B$ referring to the base area. Thus, the probability that the component fails before $t$ is (Rausand and Høyland 2004): 


$$
F_{T T F}^{(B)}(t)=1-\exp \left[-\left(\frac{t}{\eta_{B}}\right)^{\beta_{B}}\right]
$$

The failure probability of the component operating in the Arctic can be estimated by determining Weibull shape and scale parameters corresponding to the Arctic environmental conditions. To this aim, this study employs an expert-based Weibull distribution model, developed by Naseri and Barabady (2015) in analogy with PHMs. According to the underlying assumptions of PHMs (Jardine et al. 1987; Kumar and Klefsjö 1994), one can assume the component failure rate increases by a time-independent factor of $\Delta^{\prime} \in[1, \infty)$ if the component operates under Arctic environmental conditions. Thus (Naseri and Barabady 2015),

$$
\lambda_{A}(t)=\Delta^{\prime} \lambda_{B}(t)
$$

where $\lambda_{A}(t)$ and $\lambda_{B}(t)$ are Weibull failure rates of a component operating under Arctic and normal environmental conditions, respectively, given by (Rausand and Høyland 2004):

$$
\left\{\begin{array}{l}
\lambda_{A}(t)=\left(\frac{\beta_{A}}{\eta_{A} \beta_{A}}\right) t^{\beta_{A}-1} \\
\lambda_{B}(t)=\left(\frac{\beta_{B}}{\eta_{B} \beta_{B}}\right) t^{\beta_{B}-1}
\end{array}\right.
$$

where $\beta_{A}>0$ and $\eta_{A}>0$ are Weibull shape and scale parameters of a component operating in the Arctic, whereas $\beta_{B}>0$ and $\eta_{B}>0$ are those in the base area. Since $\Delta^{\prime}$ is constant, taking the derivative of Equation (2) with respect to $t$ yields (Naseri and Barabady 2015):

$$
\beta_{A}-\beta_{B}=0
$$

Substituting Equations (3) and (4) into Equation (2) gives the relationship between the scale parameters as (Naseri and Barabady 2015):

$$
\eta_{A}=\frac{\eta_{B}}{\Delta^{\frac{1}{\beta_{B}}}}
$$

Naseri and Barabady (2015) argue that eliciting expert opinions on changes in timedependent failure rate is a challenging task. To cope with such an issue, they use Equations (4) and (5) to model the changes in mean time to failure (MTTF) of a component operating in the Arctic, given by (Naseri and Barabady 2015):

$$
\operatorname{MTTF}_{A}=(1-\Delta) M T T F_{B}
$$

where $\Delta=1-1 / \Delta^{\prime} \frac{1}{\beta_{B}}$. Equation (6) states that, while the TTFs of a component are Weibull distributed, if the component failure rate is increased by a factor of $\Delta^{\prime}=1 /(1-\Delta)^{\beta_{B}}$, its MTTF decreases by a factor of $(1-\Delta)$. A formal expert judgement process is used to estimate the factor $\Delta \in[0,1)$, which is the degree of reduction in a component MTTF under Arctic operating conditions. 
Having modelled the Weibull scale parameter of the component operating in the Arctic, and considering that the shape parameter remains constant, component failure rate and its failure probability function are developed as (Naseri and Barabady 2015):

$$
\begin{aligned}
& \lambda_{A}(t)=\left[\frac{\beta_{B}}{\left[(1-\Delta) \eta_{B}\right]^{\beta_{B}}}\right] t^{\beta_{B}-1} \\
& F_{T T F}^{(A)}(t)=1-\exp \left[-\left[\frac{t}{(1-\Delta) \eta_{B}}\right]^{\beta_{B}}\right]
\end{aligned}
$$

\subsection{Modelling expert-based repair rate}

The same approach, suggested by Naseri and Barabady (2015) to modify component failure rate, is adapted to develop the repair rate of components operating in Arctic regions. In this study, it is assumed that the Arctic environmental conditions only affect the performance of the repair crew, who are exposed to the open weather (Pilcher et al. 2002), and thus extend active times to repair (TTRs). In other words, further waiting downtimes, such as administrative delays, the time required for shutting down the system before the repair and restarting it up after repair tasks are completed, delays due to spare part delivery, issuing work orders, etc., are assumed to be independent of environmental conditions. Therefore, the negative effects of the Arctic operating conditions on overall downtimes are modelled through their impact on active repair times alone.

To estimate the maintainability of the components under Arctic operating conditions, the total downtimes are divided into two categories: active TTRs and waiting downtimes. Let TTR, $W D T$, and TDT be random variables referring to active repair time, waiting downtime, and total downtime, respectively. Thus, one can write TDT as the sum of two random variables $W D T$ and TTR:

$$
T D T=W D T+T T R
$$

In other words, to predict component maintainability in Arctic regions, one needs to estimate the cumulative distribution function (CDF) of $T D T, F_{T D T}^{(A)}(t)$, which is the distribution of the sum of independent random variables WDT and TTR. Such a distribution can be obtained using either analytical methods such as convolution of the CDFs of WDT and TTR, or simulation techniques such as MC simulation.

Suppose the TTRs of a component operating in the base area are exponentially distributed (Mannan 2014) with a constant rate of $\mu_{B}$. In analogy with PHMs, it is assumed that the Arctic harsh operating conditions decrease component failure rate by a time-independent factor of $E^{\prime} \in(0,1]$, if the repair tasks are performed in an Arctic location. Thus,

$$
\mu_{A}=E^{\prime} \mu_{B}
$$

Since the mean time to repair (MTTR) of an exponential distribution is the inverse of its repair rate (Rausand and Høyland 2004), Equation (10) can be rewritten as: 


$$
\operatorname{MTTR}_{A}=\frac{1}{E^{\prime}} \operatorname{MTTR}_{B}
$$

To make Equation (11) similar to Equation (6), the opinions of experts are sought on the potential increase in MTTR of a component if the repair tasks are performed under a set of Arctic operating conditions. Denoting the combined expert opinions by $E=1 / E^{\prime}-1$, Equation (11) can be rewritten as:

$$
\operatorname{MTTR}_{A}=(1+E) M T T R_{B}
$$

Equation (12) states that, if the repair rate of a component is reduced by a factor of $E^{\prime}=$ $1 /(1+E)$, its MTTR increases by a factor of $(1+E), E \in[0, \infty)$. Using Equation (12), the CDF of the active TTRs of a component employed offshore in the Arctic can be given as:

$$
F_{\text {TTR }}^{(A)}=1-\exp \left[-\frac{1}{(1+E) M T T R_{B}} t\right]
$$

To model waiting downtimes, a lognormal distribution is used (Rausand and Høyland 2004). That is, if $\ln (W D T)$ has a normal distribution with a mean and standard deviation of $m$ and $\sigma$ (i.e., $\ln (W D T) \sim N\left(m, \sigma^{2}\right)$ ), WDT has a lognormal distribution, whose CDF is given by (Rausand and Høyland 2004):

$$
F_{W D T}(t)=\int_{0}^{t} \frac{1}{x \sigma \sqrt{2 \pi}} \exp \left[-\frac{(\ln x-m)^{2}}{2 \sigma^{2}}\right] d x=\frac{1}{2}\left[1+\operatorname{erf}\left(\frac{\ln t-m}{\sigma \sqrt{2}}\right)\right]
$$

The mean, $m^{\prime}$, and standard deviation, $\sigma^{\prime}$, of the lognormal distribution $F_{W D T}(t)$ can then be obtained using (Rausand and Høyland 2004):

$$
\begin{aligned}
m^{\prime} & =\exp \left(m+\frac{\sigma^{2}}{2}\right) \\
\sigma^{\prime} & =\sqrt{\exp \left(2 m+\sigma^{2}\right)\left[\exp \left(\sigma^{2}\right)-1\right]}
\end{aligned}
$$

To estimate the CDF of $T D T, F_{T D T}^{(A)}(t)$, an inverse transform MC sampling technique (Zio 2013) is used to sample the values of TTR and WDT from their corresponding CDFs given by Equations (13) and (14), respectively. Sampled TTRs and WDTs are then substituted into Equation (9) to obtain corresponding TDT values, which are then employed to obtain the expert-based repair distribution, i.e., the empirical CDF of TDT, $F_{T D T}^{(A)}(t)$.

\section{MC simulation modelling of system availability and throughput}

A direct MC simulation technique (Dubi 2000; Labeau and Zio 2002; Zio 2013) is used to analyse system reliability, availability and throughput performance. For this purpose, expertbased failure and repair distributions of system components should be determined. To analyse the uncertainties associated with expert judgements on equipment RAM performance, the degrees of decrease in MTTF and increase in MTTR of the components are elicited in the form 
of distributions, whose aggregation gives DM's CDFs of the changes in components MTTF and MTTR.

Fig. 1 illustrates the expert-based procedure used in this study to predict system reliability, availability and throughput. Let $F_{i, \Delta}^{D M}(\delta)$ and $F_{i, E}^{D M}(\varepsilon)$ be DM's CDFs of random variables $\Delta_{i}$ and $E_{i}$ for component $i=1, \ldots, N_{c}$, determined by aggregating expert opinions. As shown in Fig. 1 , a set of $\left\{\Delta_{i}, E_{i}\right\}$ is sampled from DM's CDFs $F_{\Delta, i}^{D M}(\delta)$ and $F_{E, i}^{D M}(\varepsilon)$, respectively, using an inverse transform sampling method (Rausand and Høyland 2004; Zio 2013). 


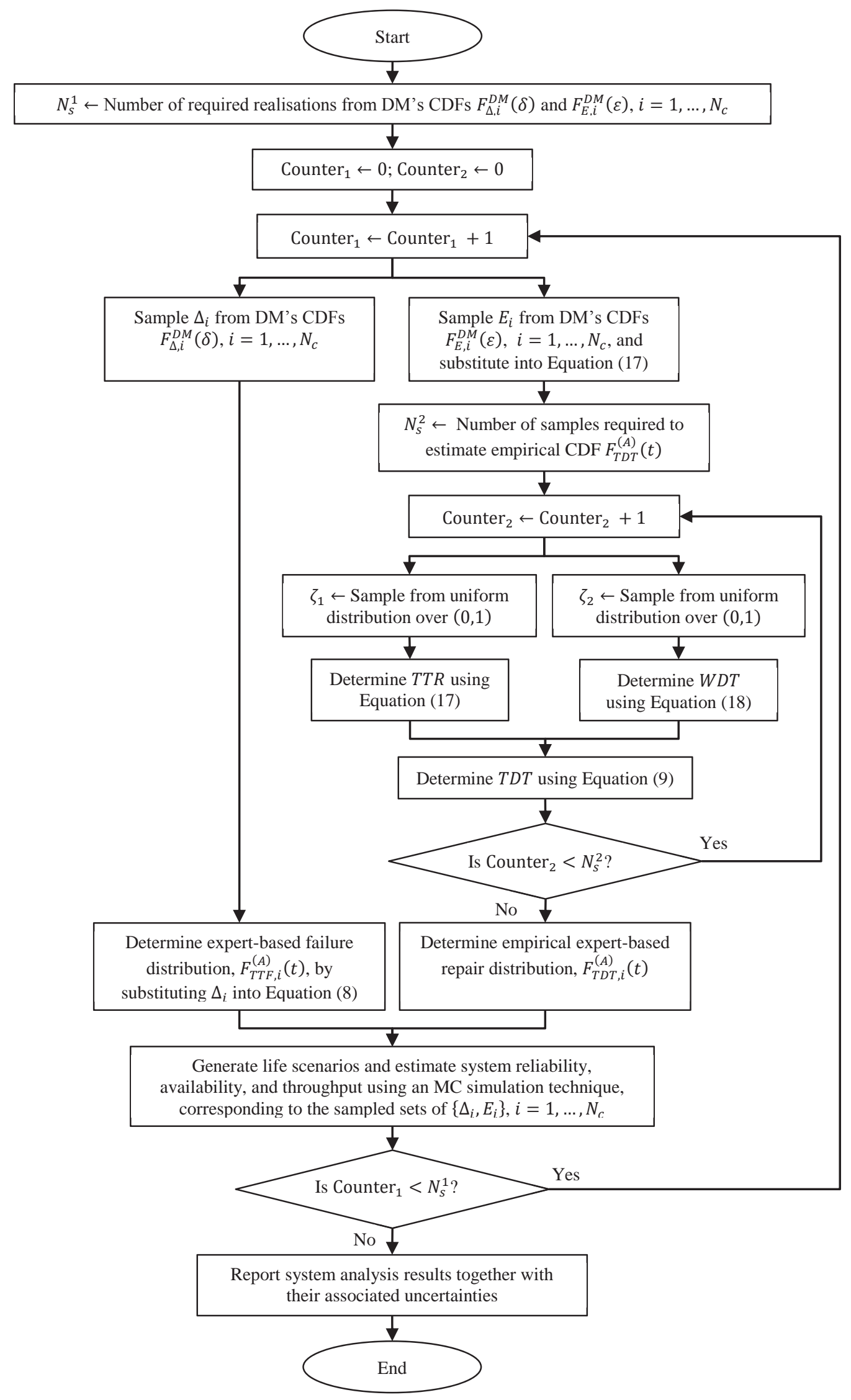

Fig. 1 Suggested MC simulation approach to estimate system RAM and throughput using expert-based failure and repair distributions, while accounting for uncertainties associated with expert judgements 
To directly obtain the expert-based failure distribution of component $i, F_{T T F, i}^{(A)}(t)$, operating in the Arctic, sampled $\Delta_{i}$ is substituted into Equation (8). The first step in determining the expert-based repair distribution, $F_{T D T, i}^{(A)}$, is to obtain the CDF of the active repair times, $F_{T T R, i}^{(A)}$, by substituting sampled $E_{i}$ into Equation (13). An MC simulation technique is then used to obtain the empirical CDF of TDT, $F_{T D T, i}^{(A)}$ by generating $N_{S}^{2}$ samples of TDT (Fig. 1). To this aim, suppose $\zeta_{1}$ and $\zeta_{2}$ are two random numbers drawn from a uniform distribution over $(0,1)$. Using an inverse transform sampling method, sampled values of TTR and WDT are generated from Equations (17) and (18), respectively:

$$
\begin{aligned}
& T T R=-(1+E) M T T R_{B} \ln \left(1-\zeta_{1}\right) \\
& W D T=\exp \left[\sigma \sqrt{2} \operatorname{erf}^{-1}\left(1-2 \ln \zeta_{2}\right)+m\right]
\end{aligned}
$$

where $\operatorname{erf}^{-1}(\cdot)$ is the inverse error function. Generated samples of TTRs and WDTs are then substituted into Equation (9) to determine corresponding values of TDT, using which the empirical CDF of $T D T, F_{T D T, i}^{(A)}(t)$ is determined.

Once failure and repair distributions for system components are determined, system reliability and availability can be estimated by performing a direct MC simulation. For this purpose, a sufficiently large number of lifetime scenarios are generated. During each simulation run, random failure and repair events are generated for system components corresponding to the stochastic character of the system, upon which the state of the components are updated. As time goes on, the system undergoes different states stochastically depending on the state of each component and system configuration. The state of the system is considered faulty if one of the pre-determined system minimal cut sets is formed.

To predict system reliability, the time points at which the system fails are stored. Such TTFs are then used to determine the empirical failure probability of the system, whose complement is system reliability. For system availability estimation, the time required to bring the system back to functioning state is also recorded as system downtime. Each simulation run stops when the simulation time reaches the operation time horizon. A detailed description of direct MC simulation is given in Dubi (2000), Labeau and Zio (2002), and Zio (2013).

The same approach can be adapted to analyse the performance of the system throughput. To this aim, it is necessary to identify the sets of the failed components leading to possible production levels. System production levels can be identified using the maximum achievable throughput of each component, system configuration, state of each component, and the rate of input to the system. With the generation of random failure and repair events, the production rate then transitions from one level to another. The time at which such transitions occur is recorded along with the length of time sustained at resulting production levels. In this regard, one may consider system conventional unavailability to be the availability of production level 0 (i.e., the state of the system is faulty and thus its production rate is zero). Similarly, 
conventional system availability is the sum of the availabilities of all production levels, excluding the production level of 0 .

As shown in Fig. 1, system reliability, availability, and throughput are estimated corresponding to each set of sampled $\left\{\Delta_{i}, E_{i}\right\}$ values. This procedure is repeated for a sufficiently large number of times ( $N_{S}^{1}$, see Fig. 1) to analyse the propagation of the uncertainties associated with expert judgements through system reliability and the availability of its different production levels.

In this study, to perform the aforementioned MC simulation runs, the following assumptions are considered:

- Components are binary.

- System has more than two states, one of which is faulty state, and the rest correspond to different production levels.

- Repair tasks are assumed to be minimal (i.e., as bad as old repair assumption).

- While a component is under repair, other components may fail.

- The repair crew is sufficient to perform several repair tasks simultaneously.

- Effects of load sharing on failure rates of the components are not considered.

\section{Case Study}

In this section, the availability and throughput of a power generation unit installed on a hypothetical Arctic offshore O\&G platform is analysed using expert judgements. The assumption is that the platform operates in the Johan Castberg field, which is located in the southwestern Barents Sea, $230 \mathrm{~km}$ north of the Norwegian coast, where life data are sparse.

\subsection{System description}

The considered power generation unit consists of four identical trains operating in parallel simultaneously (i.e., there is no stand-by train), using some portion of produced gas for electricity generation. Each train, which consists of a gas turbine (GT) and a turbine-drive generator (GEN) assembled in series configuration (Fig. 2), is practically able to produce a maximum amount of $50 \mathrm{MW}$. In total, the platform requires $150 \mathrm{MW}$. Once a train fails, the rest of the trains function at their maximum capacity to cope with the reduction in produced electricity. The power generation unit fails if all the trains fail.

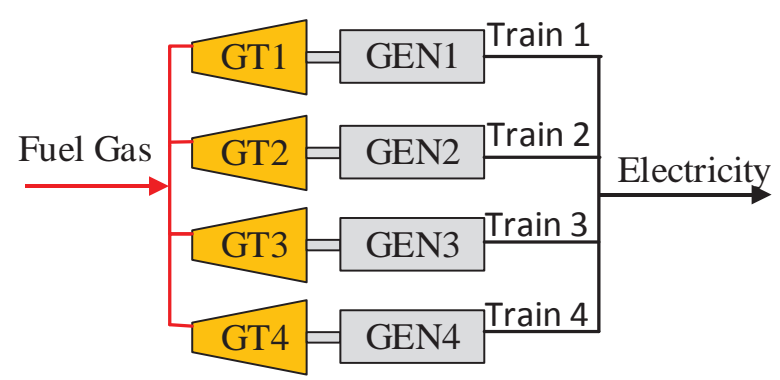

Fig. 2 Illustration of a typical power generation unit operating on an offshore O\&G platform 
The active MTTRs of GTs and GENs operating in the base area, i.e., $M T T R_{i, B}, i=1,2$, are taken from the Offshore Reliability Data Handbook (OREDA) (OREDA Participants 2009) (Table 1), which reports the active MTTRs of a wide range of equipment units installed on O\&G production facilities operating in the North and Norwegian Seas (i.e., base areas). However, the failure rates given in the OREDA Handbook are constant. This requires using an exponential failure distribution model. In this study, therefore, the shape and scale parameters of the Weibull failure distribution of GTs and GENs operating in the base area i.e., $\beta_{i, B}$ and $\eta_{i, B}$, respectively, are just assumptions, with MTTFs not dissimilar to those provided in the OREDA Handbook (Table 1).

The waiting downtime associated with each item of corrective maintenance is considered $72 \pm 10 \mathrm{hr}$, which will be fitted to a lognormal distribution given by Equation (14). By assuming $m^{\prime}=72$ and $\sigma^{\prime}=10$, the parameters of Equation (14), i.e., $m$ and $\sigma$, can be obtained using Equations (15) and (16), respectively: $m=4.2671$, and $\sigma=0.1382$.

Table 1. MTTR and Weibull failure distribution parameters of GTs and GENs operating in the base area

\begin{tabular}{|l|l|l|l|}
\hline Component & $\beta_{i, B}, \mathrm{hr}$ & $\eta_{i, B}, \mathrm{hr}$ & $\operatorname{MTTR}_{i, B}, \mathrm{hr}$ \\
\hline GT & 1.4841 & 2615 & 26 \\
\hline GEN & 1.3383 & 26378 & 20 \\
\hline
\end{tabular}

\subsection{Combining expert data}

Seven experts, $j=1, \ldots, 7$, with expertise in maintenance and reliability engineering, process engineering, mechanical engineering, and cold-climate engineering, are selected from the Norwegian academic and O\&G sectors. A questionnaire is prepared, within which experts are informed about the study objectives and the operating environment in the location of the considered O\&G production facility. Experts are then asked to give their opinions on the $5^{\text {th }}$, $50^{\text {th }}$, and $95^{\text {th }}$ quantiles of the study variables (i.e., the potential degree of decrease in MTTF of component $i=1,2, \Delta_{i},\left\{\Delta_{j i, 5 \%}, \Delta_{j i, 50 \%}, \Delta_{j i, 95 \%}\right\}$, and the potential degree of increase in its MTTR, $\left.E_{i},\left\{E_{j i, 5 \%}, E_{j i, 50 \%}, E_{j i, 95 \%}\right\}, j=1, \ldots, 7\right)$. For illustration purposes, expert data provided on the changes in the MTTF and MTTR of a GEN are presented in Table 2.

Table 2. Expert opinions on the degree of decrease in GEN's MTTF, $\Delta_{1}$ and degree of increase in its MTTR, $E_{1}$

\begin{tabular}{|l|l|l|l|l|l|l|l|}
\hline \multirow{2}{*}{$\begin{array}{l}\text { Expert } \\
\text { No. }\end{array}$} & & \multicolumn{3}{|c|}{$\Delta_{1}, \%$} & \multicolumn{3}{|c|}{$E_{1}, \%$} \\
\cline { 2 - 8 } & & $\Delta_{j 1,5 \%}$ & $\Delta_{j 1,5 \%}$ & $\Delta_{j 1,5 \%}$ & $E_{j 1,5 \%}$ & $E_{j 1,5 \%}$ & $E_{j 1,5 \%}$ \\
\hline 1 & 30 & 15 & 27.5 & 40 & 100 & 150 & 200 \\
\hline 2 & 40 & 10 & 20 & 30 & 25 & 50 & 75 \\
\hline 3 & 30 & 20 & 35 & 50 & 100 & 112.5 & 125 \\
\hline 4 & 26 & 10 & 15 & 20 & 50 & 75 & 100 \\
\hline 5 & 7 & 15 & 22.5 & 30 & 25 & 50 & 75 \\
\hline 6 & 3 & 25 & 37.5 & 50 & 75 & 100 & 125 \\
\hline 7 & 9 & 35 & 47.5 & 60 & 50 & 75 & 100 \\
\hline
\end{tabular}

The methods for combining subjectively assessed probability distributions (such as expert judgements) can be grouped into mathematical and behavioural approaches (Clemen and Winkler 1999; Clemen and Winkler 2007; Pulkkinen 1993). Mathematical aggregation methods 
consist of processes or analytical techniques, using which the DM or the analyst obtains a single combined distribution from the experts' probability distributions. Such methods are often divided into axiomatic approaches (Clemen and Winkler 1999; Cooke 1991; Genest and McConway 1990; Pulkkinen 1993) and Bayesian approaches (Clemen and Winkler 1999; Mosleh and Apostolakis 1986; Mosleh et al. 1987; Rufo et al. 2012; Winkler 1981). Among axiomatic approaches, a weighted arithmetic average of experts' probability distributions is used as a less mathematically complex technique that satisfies unanimity and marginalisation properties (Bedford and Cooke 2001; Clemen and Winkler 1999; Cooke 1991).

In this study, DM's CDFs on the degrees of reduction in components' MTTF, i.e., $F_{\Delta, i}^{D M}(\delta)$ and increase in their MTTR, i.e., $F_{E, i}^{D M}(\varepsilon), i=1,2$, are determined by combining expert judgements using weighted arithmetic averaging and Bayesian techniques.

\subsubsection{Weighted arithmetic averaging technique}

Weighted arithmetic combination of expert data is based on a linear opinion pool given by (Clemen and Winkler 1999; Clemen and Winkler 2007):

$$
F_{\Phi}^{D M}(\psi)=\sum_{j=1}^{N_{e}} w_{j} F_{\Phi}^{j}(\psi)
$$

where $F_{\Phi}^{j}(\psi)$ is expert $j$ 's $\mathrm{CDF}$ for the unknown random variable $\Phi, N_{e}$ is the number of experts, $F_{\Phi}^{D M}(\psi)$ is the combined expert CDFs for random variable $\Phi$ (i.e. DM's CDF of random variable $\Phi$ ), and the $w_{j}$ is the non-negative normalised weight for expert $j$.

There are different approaches to assign or compute the weighting factors such as equal weighting, weighting based on a set of calibration questions, weighting based on expert data, and weighting according to a set of criteria defined by the analyst or DMs (Bedford and Cooke 2001; Clemen and Winkler 1999; Meyer and Booker 1991). This study employs two different schemes to determine experts' weighting factors: equal and experience-based weighting approaches. Using an equal weighting approach, the weighting factors are given as:

$$
w_{j}=\frac{1}{N_{e}}
$$

The experience-based weighting approach is based on computing the weights proportional to the level of experience of each expert:

$$
w_{j}=\frac{y_{j}}{\sum_{j=1}^{N e} y_{j}}
$$

where $y_{j}$ is expert $j$ 's number of years of experience. Table 3 presents the computed weights using the aforementioned schemes. 
Table 3. Experts weighting factors

\begin{tabular}{|l|c|c|c|}
\hline \multirow{2}{*}{$\begin{array}{c}\text { Expert } \\
\text { No. }\end{array}$} & $\begin{array}{c}\text { Equal } \\
\text { scheme }\end{array}$ & \multicolumn{2}{c|}{$\begin{array}{c}\text { Experience- } \\
\text { based scheme }\end{array}$} \\
\cline { 2 - 4 } & $w_{j}$ & $y_{j}$ & $w_{j}$ \\
\hline 1 & 0.14286 & 30 & 0.2069 \\
\hline 2 & 0.14286 & 40 & 0.2759 \\
\hline 3 & 0.14286 & 30 & 0.2069 \\
\hline 4 & 0.14286 & 26 & 0.1793 \\
\hline 5 & 0.14286 & 7 & 0.0483 \\
\hline 6 & 0.14286 & 3 & 0.0207 \\
\hline 7 & 0.14286 & 9 & 0.0620 \\
\hline
\end{tabular}

To combine expert data, a normal distribution is fitted to the quantiles given by each expert. Using Equation (19), an MC simulation then combines estimated distributions. As an example, Fig. 3 shows the probability density function (PDF) and CDF of expert opinions on the degree of reduction in MTTF of GENs. Fig. 4 illustrates the PDF and CDF of the combined expert data (i.e., DM's PDF and CDF) using equal and experience-based weighting schemes. For instance, if expert weights are computed using an equal weighting scheme, the DM should consider a reduction of $\{10.1,27.1,55.1\} \%$ in GEN's MTTF, corresponding to the $5^{\text {th }}, 50^{\text {th }}$, and $95^{\text {th }}$ quantiles, respectively. Such reductions are $\{8.2,23.5,51.0\} \%$ if the experience-based weighting scheme is selected. By using the same approach, the DM distributions on the potential changes in MTTR of GTs and GENs as well as MTTF of GTs are estimated (Figs. 5 and 6).

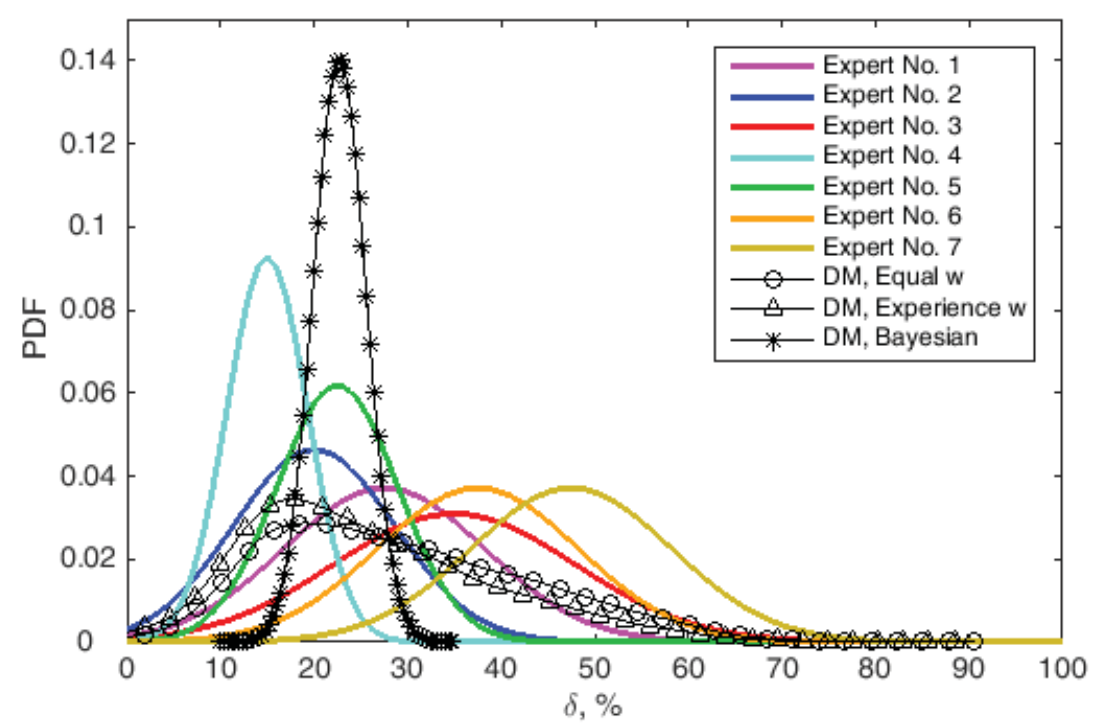

Fig. 3 PDFs of expert opinions, $f_{\Delta}^{j}(\delta)$, and DM, $f_{\Delta}^{(D M)}(\delta)$, describing the percentage of reduction in GEN's MTTF 


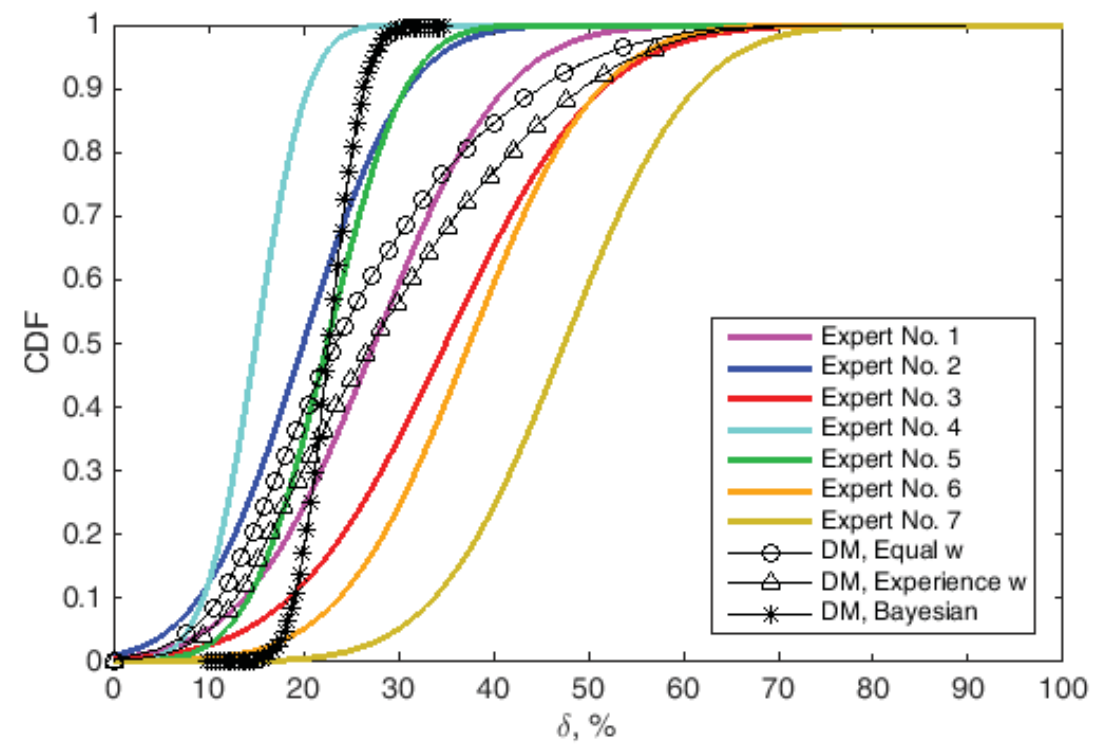

Fig. 4 CDFs of expert opinions, $F_{\Delta}^{j}(\delta)$, and DM, $F_{\Delta}^{(D M)}(\delta)$, describing the percentage of reduction in GEN's MTTF

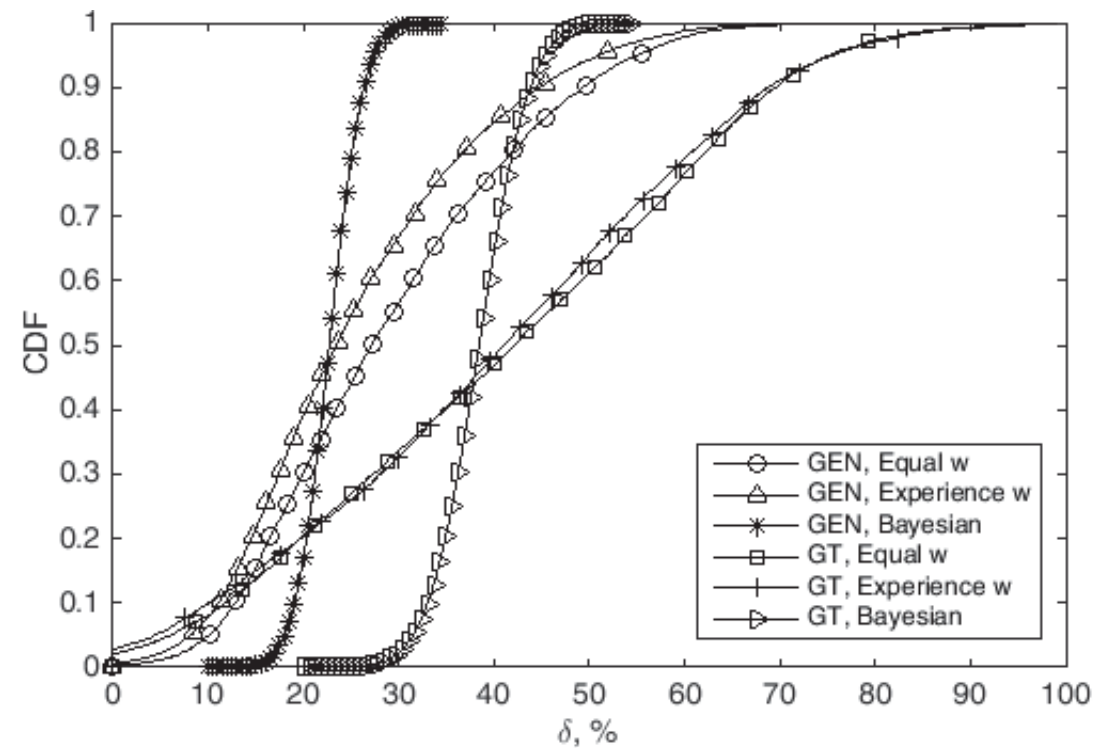

Fig. 5 DM's CDFs, $F_{i, \Delta}^{(D M)}(\delta), i=1,2$ for the percentage of reductions in MTTF of GEN and GT 


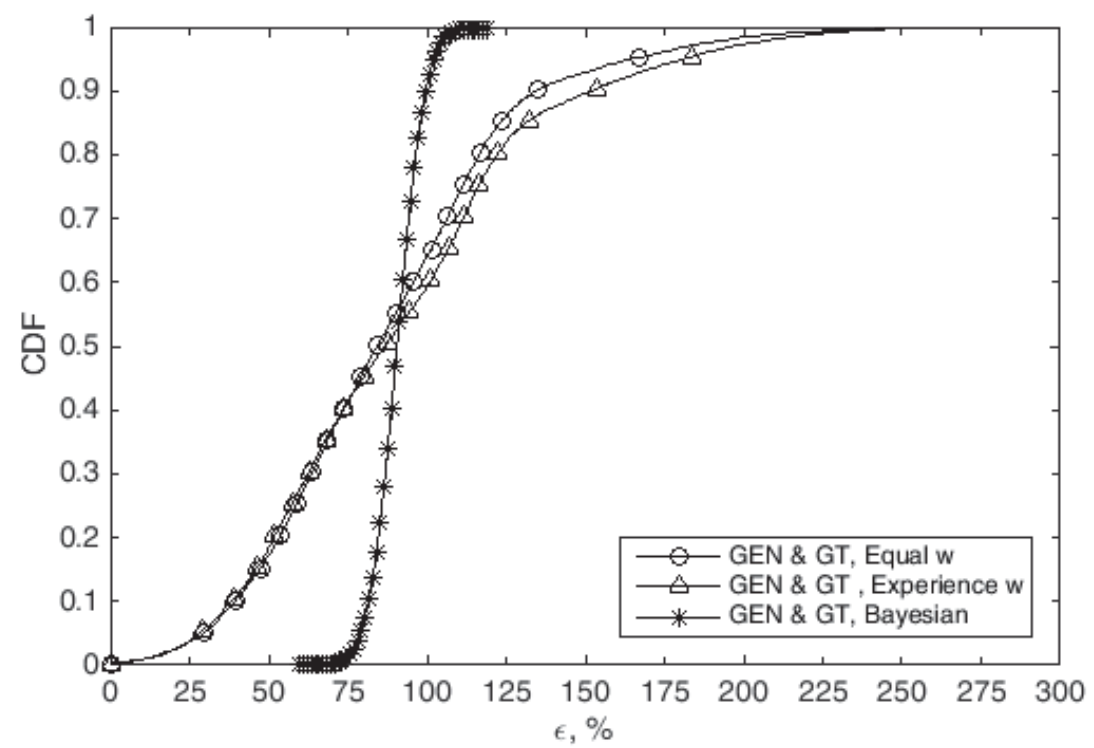

Fig. 6 DM's CDFs, $F_{i, E}^{(D M)}(\varepsilon), i=1,2$, for the percentage of increase in active MTTR of GEN and GT

\subsubsection{Bayesian technique}

A drawback in using a weighted arithmetic averaging technique is that choosing or computing experts' weights is a challenging task. That is because the DM needs to express his or her beliefs about the expertise of each expert by assigning or computing weighting factors, while accounting for experts' calibration and bias (Clemen and Winkler 1999; French 1985; Rufo et al. 2012). In comparison, Bayesian aggregation techniques are generally believed to be the most appropriate, outperforming axiomatic approaches (Clemen and Winkler 1999; French 1985; Genest and Zidek 1986; Rufo et al. 2012).

Various researchers (Clemen and Winkler 2007; Morris 1977; Mosleh and Apostolakis 1986; Podofillini and Dang 2013; Rufo et al. 2012; Winkler 1981) have developed methods based on Bayes' theorem to combine probability distributions using Bayesian techniques. This study employs the model developed by Winkler (1981), which is based on Bayesian aggregation of experts' assessments on the assumption that experts' judgements are drawn from a multivariate normal distribution, i.e., experts' distributions are assumed to be normal.

Let us denote expert $j$ 's assessed density function of the uncertain variable $\psi$ by $f^{j}(\psi)$, $j=1, \ldots, N_{e}$, which is a normal distribution with mean $m_{j}$ and standard deviation $\sigma_{j}$. Using a Bayesian framework, and by assuming that the DM's prior distribution has an improper flat density, Winkler (1981) develops the DM's posterior distribution, $F_{\Phi}^{D M}(\psi)$, as a normal distribution with mean $m^{D M}$, and standard deviation $\sigma^{D M}$, given by Equations (22) and (23), respectively:

$$
\begin{aligned}
m^{D M} & =\boldsymbol{e}^{T} \boldsymbol{\Sigma}^{-\mathbf{1}} \boldsymbol{m} / \boldsymbol{e}^{T} \boldsymbol{\Sigma}^{-\mathbf{1}} \boldsymbol{e} \\
\sigma^{D M} & =\sqrt{1 / \boldsymbol{e}^{T} \boldsymbol{\Sigma}^{-\mathbf{1}} \boldsymbol{e}}
\end{aligned}
$$


where $\boldsymbol{e}=(1, \ldots, 1)^{T}$ is a comfortable vector of ones, with $T$ standing for transpose and $\boldsymbol{m}=$ $\left(m_{1}, \ldots m_{N_{e}}\right)$ is the mean vector of experts' densities for component $i$. In Equations (22) and (23), $\boldsymbol{\Sigma}$ is the covariance matrix representing the correlation between experts' assessments for component $i$, whose elements are (Winkler 1981):

$$
\Sigma_{j k}=\rho_{j k} \sigma_{j} \sigma_{k} ; j, k=1, \ldots, N_{e}
$$

with $\rho_{j j}=1$. Correlation coefficient $\rho_{j k}$ represents the dependency of experts' densities and is determined by the DM. If the DM assumes that experts' densities are independent, $\rho_{j k}=0$.

The first step in combining experts' distribution, using the aforementioned Bayesian technique, is to fit experts' distributions to a normal distribution. In this study, according to the data given by experts, the mean $m_{j}$ and standard deviation $\sigma_{j}$ of expert $j$ 's distribution are given by:

$$
\begin{aligned}
& m_{j}=\Delta_{j, 50 \%} \\
& \sigma_{j}=\frac{\left(\Delta_{j, 5 \%}-m_{j}\right)}{\sqrt{2} \mathrm{erf}^{-1}(-0.9)}
\end{aligned}
$$

Figs. 3 and 4 show the DM's PDF and CDF of the degree of reduction in the GEN's MTTF and of increase in its MTTR, respectively, estimated using Bayesian aggregation of expert data. For instance, as shown in Fig. 4, the DM should consider a reduction of $\{19.5,22.7,25.9\} \%$ in the GEN's MTTF and an increase of $\{82.6,90.54,98.5\} \%$ in its MTTR if the Bayesian technique is used to combine experts' distributions. Using the same procedure, the DM's CDF on changes in the MTTF and MTTR of the GT can be also determined (see Figs. 5 and 6); those parameters are presented in Table 4.

Table 4. Parameters of DM's CDF for the degrees of reduction in MTTF of GEN and GT and increase in their MTTR

\begin{tabular}{|l|l|l|l|}
\hline \multirow{2}{*}{ Component } & DM's CDF & $m^{D M}$ & $\sigma^{D M}$ \\
\hline \multirow{2}{*}{ GEN } & $F_{\Delta}^{(D M)}(\delta)$ & 22.70 & 2.84 \\
\cline { 2 - 4 } & $F_{E}^{(D M)}(\varepsilon)$ & 90.54 & 7.07 \\
\hline \multirow{2}{*}{ GT } & $F_{\Delta}^{(D M)}(\delta)$ & 38.42 & 4.21 \\
\cline { 2 - 4 } & $F_{E}^{(D M)}(\varepsilon)$ & 90.54 & 7.07 \\
\hline
\end{tabular}

As shown in Fig. 5, an aggregation of expert judgements using Bayesian methods leads to the lower probabilities of reduction in the MTTF of GENs and GTs and their MTTR. Although the use of equal- and experience-based weighting schemes results in close estimations for the reduction in GTs' MTTF, it leads to different degrees of decrease in the MTTF of GENs.

Moreover, it should be noted that the random variable $E$ has the same distribution for both of the components GEN and GT (Fig. 6). That is because variable $E$ refers to the reductions in 
MTTR of the components due to the adverse effects of the harsh Arctic operating environment on human performance, which is considered the same for GENs and GTs.

\subsection{Results and discussion}

\subsubsection{Production level identification}

The power generation unit has four trains, which are expected to deliver $150 \mathrm{MW}$ in total. Therefore, each train is expected to produce $37.5 \mathrm{MW}$, which is $75 \%$ of its maximum achievable capacity, i.e., $50 \mathrm{MW}$. Once a train fails, the required electricity should be generated using the remaining trains. For instance, if Train 1 fails, each of the remaining three trains will deliver 50 MW, i.e., operating at $100 \%$ of their maximum achievable capacity, in order to meet the required electricity production of 150 MW. Since each train consists of a GT and GEN, arranged in a series, the train fails if either GT or GEN fails (see Fig. 2).

Therefore, by identifying the status of each train, i.e., faulty or functioning, one can determine four possible power generation scenarios $P G S_{s}, s=1, \ldots, 4$ resulting in four production levels of 50,100,150, and 0 MW. Table 5 presents such scenarios, their production levels, and the corresponding possible functioning configurations of the system.

Table 5. Power generation scenarios and their corresponding system functioning configurations

\begin{tabular}{|l|l|l|l|}
\hline $\begin{array}{l}\text { Power generation } \\
\text { scenario, } P G S_{s}\end{array}$ & $\begin{array}{l}\text { Overall power } \\
\text { generation, } \\
\text { MW }\end{array}$ & $\begin{array}{l}\text { Throughput of } \\
\text { each train, MW } \\
\text { (Capacity \%) }\end{array}$ & $\begin{array}{l}\text { Functioning configurations of the system, } \\
\text { leading to production level } P G S_{s} \text {; (TR stands } \\
\text { for electricity generation train) }\end{array}$ \\
\hline 1 & 50 & $50(100 \%)$ & TR1; TR2; TR3; TR4 \\
\hline 2 & 100 & $50(100 \%)$ & $\begin{array}{l}\text { TR1 \& TR2; TR1 \& TR3; TR1 \& TR4; } \\
\text { TR2 \& TR3; TR2 \& TR4; TR3 \& TR4 }\end{array}$ \\
\hline 3 & 150 & $50(100 \%)$ & $\begin{array}{l}\text { TR1 \& TR2 \& TR3; } \\
\text { TR1 \& TR2 \& TR4; } \\
\end{array}$ \\
& & & $\begin{array}{l}\text { TR1 \& TR3 \& TR4; } \\
\text { TR2 \& TR3 \& TR4 }\end{array}$ \\
\hline 4 & 0 & $37.5(75 \%)$ & TR1 \& TR2 \& TR3 \& TR4 \\
\hline
\end{tabular}

For example, the production level of $150 \mathrm{MW}$ can be reached while all the trains are functioning at $75 \%$ of their maximum achievable capacity (i.e. $37.5 \mathrm{MW}$ ). The other possibility is that three trains are functioning (one train is failed), but each functioning train operates at its full achievable capacity of $50 \mathrm{MW}$. Therefore, the power generation unit can produce $150 \mathrm{MW}$ by means of five different configurations (Table 5).

As operation time goes on, system components may fail and be under repair. Such stochastic changes in the state of the components lead to different system configurations and thus result in one of the power generation scenarios, $P G S_{s}$, with a specific amount of generated power (Table 5).

\subsubsection{Availability and throughput analysis}

The concept of availability is extended by redefining the required function of the system as producing a certain amount of electricity, i.e., 0, 50, 100, and $150 \mathrm{MW}$. In this regard, four sets 
of system instantaneous availability can be considered, corresponding to each scenario. Note that, according to the conventional definition of system availability, the availability of $P G S_{4}, 0$ MW, is actually system unavailability. Similarly, system overall availability is the sum of the availabilities of $P G S_{1}, P G S_{2}$, and $P G S_{3}$.

Fig. 7 shows the instantaneous availabilities of each scenario under the assumption of minimal repair and considering that the system is operating in the base area for three years. It can be seen that the system unavailability (i.e., availability of $P G S_{4}, 0 \mathrm{MW}$ ) increases with time due to the aging of GTs and GENs. Since system components fail more frequently, the number of occasions on which the system configuration corresponds to power generation scenarios $P G S_{1}, P G S_{2}$, and $P G S_{4}$ increases, and thus their availabilities rise with time. This consequently causes a reduction in the availability of 150 -MW-delivering $P G S_{3}$. The corresponding mean availabilities are reported in Table 6. For instance, while system mean unavailability (i.e., availability of $P G S_{4}, 0 \mathrm{MW}$ ) is approximately $0.001 \%$ during the first three years, the mean availability of the unit producing $50 \mathrm{MW}, 100 \mathrm{MW}$, and $150 \mathrm{MW}$ is $0.056 \%, 1.398 \%$, and 98.545\%, respectively. Within the context of conventional availability, although the system overall mean availability is $99.999 \%$ and is considered a highly available system, it meets the requirement of generating $150 \mathrm{MW}$ only during $98.545 \%$ of its mission time.
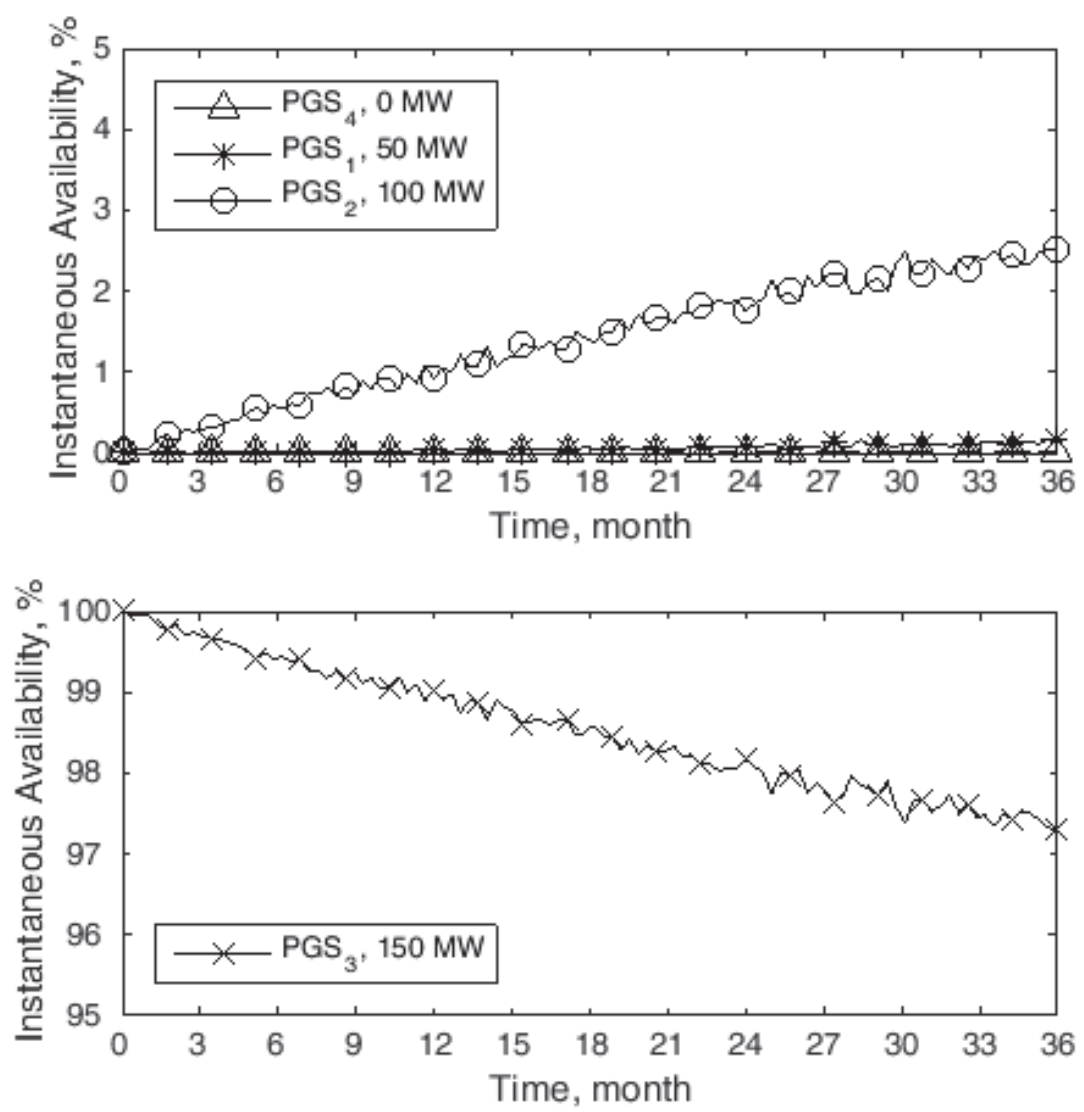

Fig. 7 Point availability of power generation unit in the base area, corresponding to power generation scenarios $P G S_{S}$ 
Table 6. Mean availability of power generation unit in the base area and the Barents Sea

\begin{tabular}{|c|c|c|c|c|c|c|c|c|c|c|c|}
\hline \multirow{2}{*}{\multicolumn{2}{|c|}{$\begin{array}{l}\text { Electricty } \\
\text { Production }\end{array}$}} & \multicolumn{10}{|c|}{ Mean availability, \% } \\
\hline & & \multirow{3}{*}{$\begin{array}{l}\text { Base } \\
\text { area }\end{array}$} & \multicolumn{9}{|c|}{ Barents Sea } \\
\hline \multirow{2}{*}{$P G S_{S}$} & \multirow{2}{*}{$\begin{array}{l}\text { Total } \\
\text { MW }\end{array}$} & & \multicolumn{3}{|c|}{ Equal-based } & \multicolumn{3}{|c|}{ Experience-based } & \multicolumn{3}{|c|}{ Bayesian } \\
\hline & & & $5^{\text {th }}$ & $50^{\text {th }}$ & $95^{\text {th }}$ & $5^{\text {th }}$ & $50^{\text {th }}$ & $95^{\text {th }}$ & $5^{\text {th }}$ & $50^{\text {th }}$ & $95^{\text {th }}$ \\
\hline 1 & 50 & 0.056 & 0.09 & 0.22 & 1.30 & 0.09 & 0.20 & 0.99 & 0.25 & 0.39 & 0.58 \\
\hline 2 & 100 & 1.398 & 1.92 & 3.32 & 9.82 & 1.96 & 3.10 & 8.30 & 3.59 & 4.70 & 6.04 \\
\hline 3 & 150 & 98.545 & 88.62 & 96.45 & 97.95 & 90.63 & 96.69 & 97.94 & 93.30 & 94.89 & 96.14 \\
\hline 4 & 0 & 0.001 & 0.002 & 0.002 & 0.070 & 0.001 & 0.005 & 0.047 & 0.001 & 0.013 & 0.023 \\
\hline
\end{tabular}

To analyse the performance of the power generation unit under Arctic operating conditions, the $90 \%$ double-sided confidence intervals of production level availabilities are reported. The estimated confidence bounds give an indication as to the propagation of the uncertainties associated with expert opinions. For example, Fig. 8 shows the $5^{\text {th }}, 50^{\text {th }}$, and $95^{\text {th }}$ quantiles of the instantaneous availability of a power generation unit producing $150 \mathrm{MW}$ for an operation time horizon of three years. As can be seen, the production level availability is considerably lower than that estimated for the base area. Moreover, it can be seen that different techniques for expert opinion aggregation result in different availabilities. The lowest availability levels are estimated using an equal-based weighting scheme, whereas an experience-based weighting approach and Bayesian technique lead to comparatively higher availabilities. The DM's CDF $F_{\Delta}^{(D M)}(\delta)$ confirms this (Fig. 5), as the highest reductions in the components' MTTF are predicted using an equal-based weighting approach. Additionally, the availability of $P G S_{3}, 150$ MW, estimated using the DM's CDF obtained by Bayesian aggregation of the experts' distributions, has lower levels of uncertainties compared to those estimations based on the DM's CDFs aggregated using a weighted arithmetic averaging method.

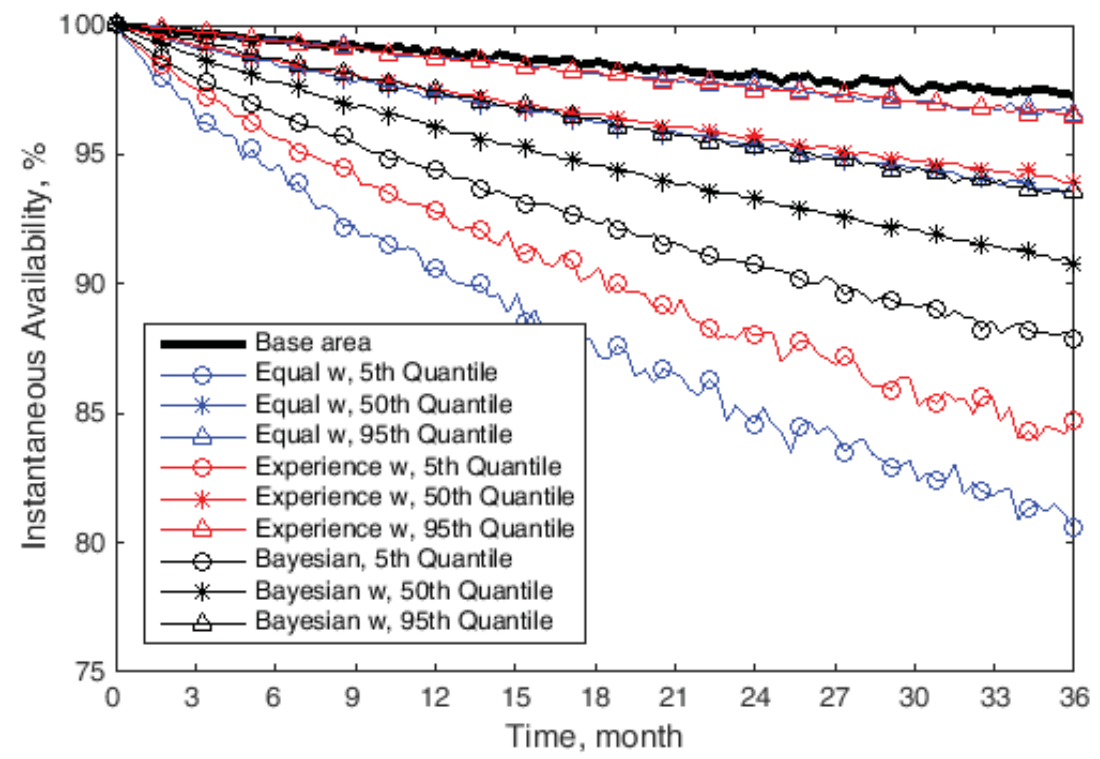

Fig. 8 Instantaneous availability of power generation unit in the base are and the Barents Sea, corresponding to system configurations leading to $150 \mathrm{MW}$, using different methods to aggregate expert judgements 
From the viewpoint of industrial practices, it is beneficial to estimate the mean availabilities of the different production levels, $P G S_{s}, s=1, \ldots, 4$. Considering that such estimations are subject to the uncertainties associated with expert opinions, one can estimate the CDFs of mean availabilities and compare them with the deterministic estimation made for the base area (Fig. 9). As shown in Fig. 9, Arctic operating conditions increase the mean availability of scenarios $P G S_{1}$ (Fig. 9a), $P G S_{2}$ (Fig. 9b), and $P G S_{4}$, i.e., conventional unavailability (Fig. 9d). Such rises in mean availabilities cause a reduction in the mean availability of $P G S_{3}$ (Fig. 9c). In other words, as the components of the system age, the probability of the system delivering $0 \mathrm{MW}, 50 \mathrm{MW}$, and $100 \mathrm{MW}$ increases, consequently leading to a reduction in the probability of delivering $150 \mathrm{MW}$.

The $5^{\text {th }}, 50^{\text {th }}$, and $95^{\text {th }}$ quantiles of the mean availabilities of different power generation scenarios, which are estimated using the Bayesian technique and a weighted arithmetic averaging method, are reported in Table 6. For instance, in the base area, the availability of producing $150 \mathrm{MW}$ is about $98.545 \%$, a figure that reduces to $96.45,96.69$, and $94.89 \%$, corresponding to the $50^{\text {th }}$ quantile, when estimations employ an equal-based weighting scheme, an experience-based weighting scheme, and the Bayesian technique, respectively.
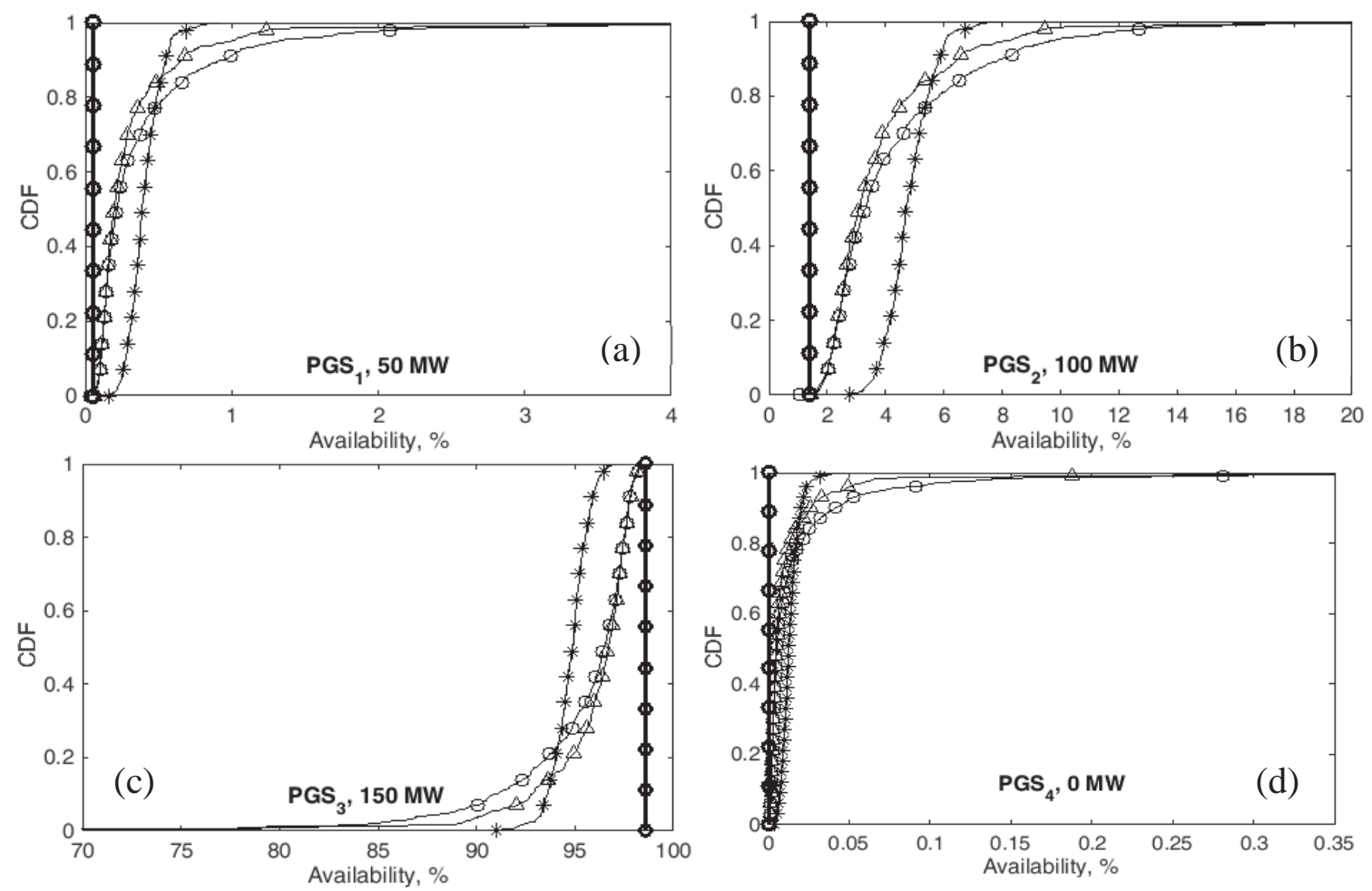

G-Base area $\square-$ Equal $w \longrightarrow \Delta$ Experience $w \rightarrow$ - Bayesian

Fig. 9 CDF of mean availabilities of power generation unit in the Barents Sea, corresponding to different power generation scenarios estimated using different expert weighting schemes

The proposed methodology in this study is also capable of estimating system reliability using first-time-to-failures (FTTFs) (Rausand and Høyland 2004). To this aim, during each MC simulation run, the time point corresponding to the first system failure is recorded. The CDF of 
FTTFs is then the failure probability function, and its complementary is considered system reliability. Fig. 10 compares the reliability of the power generation unit operating in the Barents Sea, corresponding to the three considered methods of aggregating expert judgements, with that estimated for the base area after three years of operation. As can be seen, the level of reliability of the power generation unit in the Barents Sea is considerably lower than that of the base area. Similar to system availability, a weighted linear combination of expert data using equal weights results in the lowest reliability predictions. Reliability of the system in the base area reaches $97.87 \%$ after three years, whereas it is about $20.70,88.00$, and $96.10 \%$ corresponding to the $5^{\text {th }}$, $50^{\text {th }}$, and $95^{\text {th }}$ quantiles estimated using equal-based weighting factors. If expert opinions are aggregated using experience-based weights and Bayesian technique, such a reduction is about $34.90,89.60,96.10 \%$ and $60.60,75.20,85.70 \%$, corresponding to the $5^{\text {th }}, 50^{\text {th }}$, and $95^{\text {th }}$ quantiles, respectively.

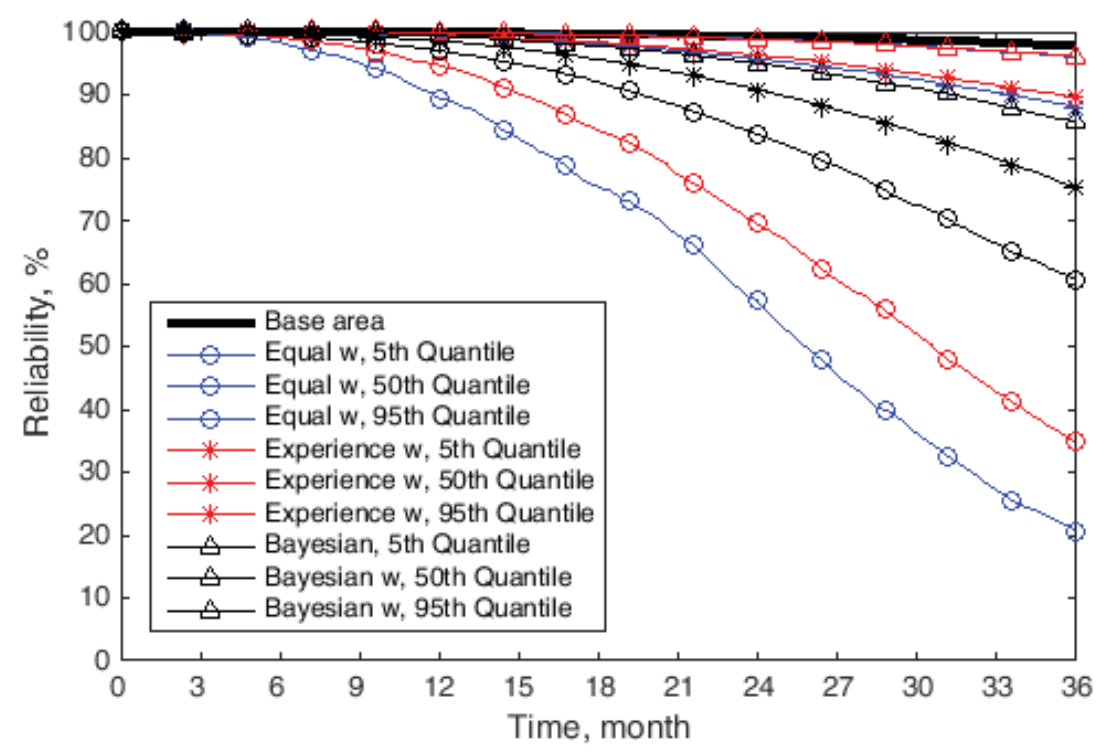

Fig. 10 Reliability of power generation unit in the base area and the Barents Sea using different methods of aggregating expert judgements

\section{Conclusion}

In this study, an expert-based model is developed to predict system availability and throughput while taking into account the effects of Arctic operating conditions. The underlying principle of the developed model is combining the life data collected in a normal-climate region with expert judgements to modify the conventional RAM models. Such a model takes into account waiting downtimes with a lognormal distribution as well as the adverse impact of harsh weather conditions on maintenance crew performance that leads to extended active repair times with an exponential distribution. Failure distributions of the components are estimated by adapting an expert-based Weibull failure distribution function.

Based on the proposed model and considering expert judgement uncertainties, a step-bystep direct MC simulation approach is suggested in this study, through which the proposed aggregated expert judgements modify the failure rate and active repair rate of each component. 
Expert-based active repair distribution is further combined with waiting downtime distribution. Using the proposed approach, system reliability, availability, and throughput are analysed after identifying system production levels and possible system configurations that lead to such production levels. It also investigates the propagation of expert judgement uncertainties through system RAM and throughput.

Uncertainties associated with expert data are accounted for by eliciting the quantiles of expert data. Among different techniques available for combining experts' distributions, a weighted arithmetic averaging approach and a Bayesian method are used, of which the Bayesian combination of expert data led to a less uncertain prediction of system availability and throughput, in this study.

As illustrated in the case study, although the impact of harsh Arctic operating conditions on system availability may be considered negligible, especially in highly reliable systems (e.g., a four-train redundant power generation unit), the harsh operating conditions have a considerable effect on the throughput of the system. The results of the study can be used to provide technological solutions to DMs in terms of plant modifications, cost-benefit analysis, and implementation of winterisation measures.

\section{References}

Ansell JI, Philipps MJ (1997) Practical aspects of modelling of repairable systems data using proportional hazards models Reliability Engineering \& System Safety 58:165-171 doi:http://dx.doi.org/10.1016/S0951-8320(97)00026-4

Artiba A, Riane F, Ghodrati B, Kumar U (2005) Reliability and operating environment-based spare parts estimation approach: a case study in Kiruna Mine, Sweden Journal of Quality in Maintenance Engineering 11:169-184

Barabadi A, Barabady J, Markeset T (2011a) Maintainability analysis considering time-dependent and time-independent covariates Reliability Engineering \& System Safety 96:210-217 doi:http://dx.doi.org/10.1016/j.ress.2010.08.007

Barabadi A, Barabady J, Markeset T (2011b) A methodology for throughput capacity analysis of a production facility considering environment condition Reliability Engineering \& System Safety 96:1637-1646 doi:http://dx.doi.org/10.1016/j.ress.2011.09.001

Barabadi A, Gudmestad OT, Barabady J (2015) RAMS data collection under Arctic conditions $\begin{array}{lllll}\text { Reliability Engineering } \quad \& \quad \text { System } & \text { Safety } & \text { 135:92-99 }\end{array}$ doi:http://dx.doi.org/10.1016/j.ress.2014.11.008

Barabadi A, Markeset T (2011) Reliability and maintainability performance under Arctic conditions International Journal of System Assurance Engineering and Management 2:205-217 doi:http://dx.doi.org/10.1007/s13198-011-0071-8

Bedford T, Cooke R (2001) Probabilistic risk analysis: foundations and methods. Cambridge. Cambridge University Press,

Clemen RT, Winkler RL (1999) Combining probability distributions from experts in risk analysis Risk analysis 19:187-203

Clemen RT, Winkler RL (2007) Aggregating probability distributions. In: Edwards W, Miles Jr RF, Von Winterfeldt D (eds) Advances in decision analysis: from foundations to applications. Cambridge University Press, Cambridge, pp 154-176

Cooke RM (1991) Experts in uncertainty: opinion and subjective probability in science. Oxford University Press,

Dale CJ (1985) Application of the proportional hazards model in the reliability field Reliability Engineering 10:1-14 doi:http://dx.doi.org/10.1016/0143-8174(85)90038-1 
Dubi A (2000) Monte Carlo Applications in Systems Engineering. Wiley, Chichester:

French S (1985) Group Consensus Probability Distributions: A Critical Survey. In: Bernardo JM, Groot MHD, Lindley DV, Smith AFM (eds) Bayesian Statistics. Elsevier, North Holland, pp 183-201

Gao X, Barabady J, Markeset T (2010) An approach for prediction of petroleum production facility performance considering Arctic influence factors Reliability Engineering \& System Safety 95:837-846 doi:http://dx.doi.org/10.1016/j.ress.2010.03.011

Genest C, McConway KJ (1990) Allocating the weights in the linear opinion pool Journal of Forecasting 9:53-73 doi:http://dx.doi.org/10.1002/for.3980090106

Genest C, Zidek JV (1986) Combining probability distributions: A critique and an annotated bibliography Statistical Science 1:114-135

Gudmestad OT, Karunakaran D (2012) Challenges Faced by the Marine Contractors Working in Western and Southern Barents Sea. Paper presented at the OTC Arctic Technology Conference, 3-5 December, Houston, Texas, USA,

ISO (2001) ISO 12494: Atmospheric Icing of Structures. ISO, Geneva

ISO (2010) ISO 19906: Petroleum and Natural Gas Industries - Arctic Offshore Structures. ISO, Geneva

Jardine A, Anderson P, Mann D (1987) Application of the Weibull proportional hazards model to aircraft and marine engine failure data Quality and reliability engineering international 3:77-82

Kumar D, Klefsjö B (1994) Proportional hazards model: a review Reliability Engineering \& System Safety 44:177-188 doi:http://dx.doi.org/10.1016/0951-8320(94)90010-8

Labeau PE, Zio E (2002) Procedures of Monte Carlo transport simulation for applications in system engineering Reliability Engineering \& System Safety 77:217-228 doi:http://dx.doi.org/10.1016/S0951-8320(02)00055-8

Løset S, Shkhinek K, Gudmestad OT, Strass P, Michalenko E, Frederking R, Kärnä T (1999) Comparison of the physical environment of some Arctic seas Cold Regions Science and Technology 29:201-214 doi:http://dx.doi.org/10.1016/S0165-232X(99)00031-2

Mannan S (2014) Lees' Process Safety Essentials: Hazard Identification, Assessment and Control. Butterworth-Heinemann, Oxford. doi:http://dx.doi.org/10.1016/B978-1-85617-776-4.00004-X

Meyer MA, Booker JM (1991) Eliciting and Analyzing Expert Judgement - A Practical Guide. Academic Press, London. doi:http://dx.doi.org/10.1137/1.9780898718485

Morris PA (1977) Combining expert judgments: A Bayesian approach Management Science 23:679693

Mosleh A, Apostolakis G (1986) The assessment of probability distributions from expert opinions with an application to seismic fragility curves Risk Analysis 6:447-461

Mosleh A, Bier VM, Apostolakis G (1987) Methods for the elicitation and use of expert opinion in risk assessment: Phase 1, A critical evaluation and directions for future research (NUREG/CR4962). U.S. Nuclear Regulatory Commission, Washington D.C.

Murthy DNP, Xie M, Jiang R (2004) Weibull Models. John Wiley \& Sons, New Jersey

Naseri M, Barabady J (2013) Offshore drilling activities in Barents Sea: Challenges and considerations. Paper presented at the Proceedings of the 22nd International Conference on Port and Ocean Engineering under Arctic Conditions (POAC), June 9-13, Espoo, Finland,

Naseri M, Barabady J (2015) Reliability Analysis of Arctic Oil and Gas Production Plants: Accounting for the Effects of Harsh Weather Conditions Using Expert Data Submitted to a journal for publication

OREDA Participants (2009) Offshore Reliability Data Handbook 5th ed. OREDA Participants, Trondhim

Pilcher JJ, Nadler E, Busch C (2002) Effects of hot and cold temperature exposure on performance: a meta-analytic review Ergonomics 45:682-698

Podofillini L, Dang VN (2013) A Bayesian approach to treat expert-elicited probabilities in human reliability analysis model construction Reliability Engineering \& System Safety 117:52-64 doi:http://dx.doi.org/10.1016/j.ress.2013.03.015

Pulkkinen U (1993) Methods for combination of expert judgements Reliability Engineering \& System Safety 40:111-118 doi:http://dx.doi.org/10.1016/0951-8320(93)90101-4

Rausand M, Høyland A (2004) System reliability theory: models, statistical methods, and applications vol 396. John Wiley \& Sons, 
Rufo MJ, Pérez CJ, Martín J (2012) A Bayesian approach to aggregate experts' initial information Electronic Journal of Statistics 6:2362-2382

Stapelberg RF (2009) Handbook of reliability, availability, maintainability and safety in engineering design. Springer,

Winkler RL (1981) Combining probability distributions from dependent information sources Management Science 27:479-488

Zio E (2013) The Monte Carlo Simulation Method for System Reliability and Risk Analysis. Springer, London 